\title{
FÉRRIZ Y CABRERO: LECCIONES DE UNA DESCONOCIDA Y PARADIGMÁTICA COLABORACIÓN ENTRE FOTÓGRAFO Y ARQUITECTO
}

\author{
Iñaki Bergera, Cristina Jiménez
}

El creciente interés por investigar y analizar las relaciones entre arquitectura y fotografía puede abordarse desde enfoques generales o dimensiones más especulativas pero también desde casos de estudio específicos. La posibilidad de tener acceso directo tanto a las fotografías en papel del archivo del arquitecto Asís Cabrero como a los negativos del fotógrafo Férriz nos permite analizar en profundidad un material inédito de una colaboración paradigmática entre un arquitecto y un fotógrafo prácticamente desconocido hasta la fecha. La condición exclusiva de esta relación, la calidad de las imágenes y la sinergia entre ambos profesionales apuntan claves, lecciones en suma, para seguir profundizando en el papel y los usos de la imagen construida y en sus implicaciones en el devenir arquitectónico.

Palabras clave: Fotografía de arquitectura, arquitecto-fotógrafo, Cabrero, Férriz, España Keywords: Architectural Photography, Architect-Photographer, Cabrero, Férriz, Spain

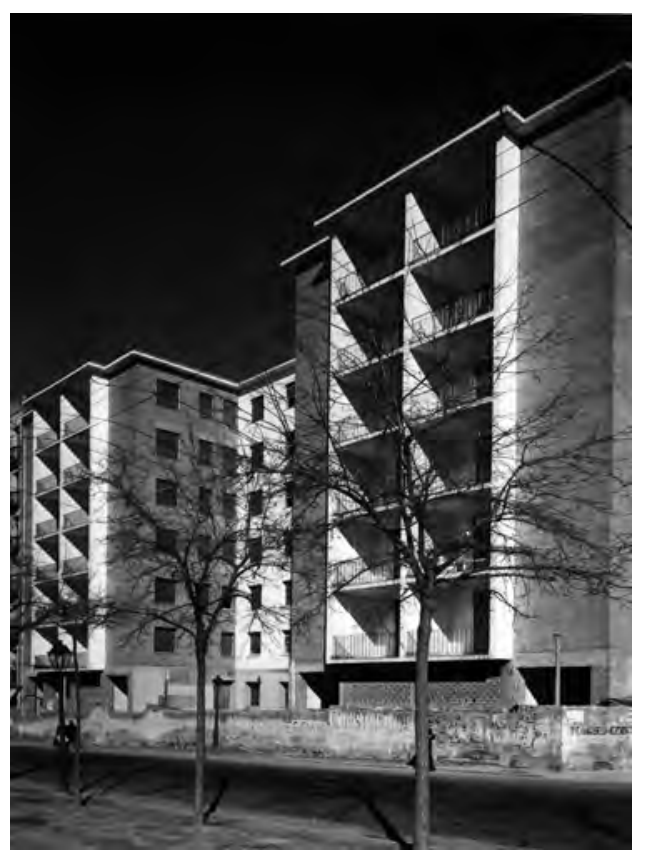

1

Dentro de los numerosos encargos que Francisco de A sís Cabrero (1912-2005) recibió durante los autárquicos años 40 por el hecho de ser arquitecto en plantilla de la 0 bra Sindical del Hogar - arquitecto jefe del departamento técnico desde $1943^{1}-$, nos encontramos con las viviendas en el paseo Francisco Silvela de M adrid (Fig. 1), construidas en 1945. Titulado en 1942 por la Escuela de A rquitectura de M adrid, previamente había realizado para el mismo organismo otros grupos de viviendas protegidas, singularmente en B éjar (Salamanca). Los reportajes fotográficos de estas viviendas conservados en el archivo del arquitecto ${ }^{2}$ son de autor desconocido ${ }^{3}$. En este proyecto de 1945 encontramos por primera vez el sello 'Férriz, fotógrafo industrial' (Fig. 2) en el reverso de las fotografías. Pero no sólo de J esús García Férriz (1900-1988); también se conservan varias fotografías de un reportaje del mismo edificio firmado por K indel (J oaquín del Palacio). Tres años más tarde, en 1948, esta situación de reportaje doble - uno de Férriz y otro de Kindel- se repetirá con las viviendas grupo 'V irgen del Pilar', también para la OSH en M adrid. Salvo muy contadas excepciones, como Ios reportajes realizados por Paco Gómez ${ }^{4}$ de la sede del diario Arriba (M adrid, 1960-1962) y del Á rea de Servicios en el kilómetro 3 de la autopista entre Villal ba y Villacastín (M adrid, 1971), no es posible datar desde entonces y hasta que en 1973 fotografiara el proyecto de Ayuntamiento de A I corcón otras colaboraciones entre A sís Cabrero y otro fotógrafo que no
Fig. 1. Viviendas en el paseo Francisco Silvela (Madrid, 1945). Arquitecto: Francisco Cabrero. Fotógrafo: Férriz. (C) Familia Férriz. AGUN/273.

Fig. 2. Sello original de "Férriz, Fotógrafo industrial". (C) Alberto Férriz (nieto)

* Este artículo se inscribe dentro de los objetivos investigadores y de divulgación del proyecto de investigación FAME del Programa Nacional de Proyectos de Investigación Fundamental en el marco del VI Programa Nacional de Investigación Científica, Desarrollo e Innovación Tecnológica 20082011 (Ref. HAR2012-34628), del Ministerio de Economía y Competitividad, y su contenido forma parte del material de una tesis en curso.

1. Cfr. DELGADO ORUSCO, Eduardo, "La OSH y las normas de Cabrero", en A.A.V.V., Un siglo de vivienda social: 1903-2003 [catálogo de exposición], Ministerio de Fomento, Ayuntamiento de Madrid, Consejo Económico y Social, Madrid, 2003, tomo II, pp. 41-43

2. Desde el año 2014 el archivo fotográfico de Asís Cabrero está depositado en el Archivo General de la Universidad de Navarra, legado AGUN/273. El archivo de arquitectura se encuentra desde 2005 en el Servicio Histórico de la Fundación COAM, legado FCT.

3. Como excepción, algunas pocas que llevan el sello de J. Requena y otras, tomas aéreas, fueron realizadas por empresas especializadas.

4. Sobre Francisco Gómez, otro de los destacados fotógrafos de la modernidad arquitectónica -en especial por su actividad como fotógrafo oficial de la revista Arquitectura-, cfr. BERNAL, Amparo, "Paco Gómez: fotógrafo de la revista Arquitectura", en Ra: Revista de Arquitectura, 2012, 14, pp. 81-88 


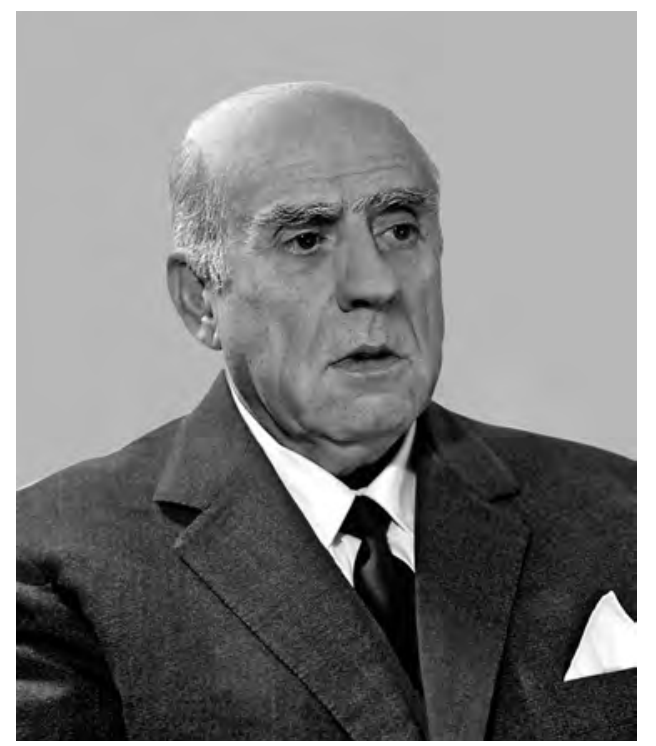

Fig. 3. Retrato de Jesús García Férriz. @ Alberto Férriz (nieto).

sea Férriz. De forma inversa, y a pesar de haber sido colaborador de la revista Arquitectura desde 1928 hasta 1931, a partir de los años 40 y también salvo casos aislados ${ }^{5}$, no es senci$\|$ o acreditar que Férriz hiciera reportajes de arquitectura al uso para otros arquitectos. Esta doble constatación pone sobre la mesa un caso de estudio único, inexplorado hasta la fecha y de enorme interés especulativo para ahondar en los entresijos del maridaje arquitecturafotografía, máxime si documental mente se tiene acceso tanto a las copias en papel del archivo del arquitecto como a los negativos originales del fotógrafo.

La estrecha y fiel relación profesional entre Cabrero y Férriz constituye así, en el ámbito de la arquitectura moderna española, un caso único de radical confianza y complicidad entre un arquitecto y su fotógrafo. Conocemos sin duda casos el ocuentes en el contexto internacional -como Le Corbusier y Lucien Hervé, Richard N eutra y Julius Shulman, L uis Barragán y A rmando Sal as Portugal o Frank L loyd W right y Pedro G uerrero- y también en España -J osé A ntonio Coderch y Francesc Català-R oca o J osé L uis Fernández del A mo y K indel- pero en ninguno de los dos escenarios nos encontramos con un ejemplo tan notorio de consentida exclusividad. Al margen de los datos que se pueden aportar para dar razón de este hecho, e incluso de las hipótesis que se puedan formular al respecto, este caso de estudio que se aborda en el presente texto nos permite apuntalar de forma crítica y rigurosa - por su extrema y contundente nitidez ejemplarizante y por los datos documentales inéditos que se aportan- los mimbres que tejen el discurso relacional entre el hecho creativo del arquitecto, el proyecto, y la forma de documentarlo y narrarlo visualmente mediante fotografías. A bordamos así, bajo una nueva práctica relacional entre los agentes respectivos, las sinergias entre arquitectura y fotografía, que tanto interés suscitan, para avalar y demandar un estatuto particular propio al rol que desempeña la imagen de la arquitectura en su gestación y transmisión mediática, historiográfica y disciplinar. Si bien la figura y reconocida fortuna crítica del arquitecto A sís Cabrero está ya acrisolada dentro de los relatos de la arquitectura moderna española - y por tanto no será objeto de atención aquíi ${ }^{6}$, hasta la fecha la firma familiar de fotógrafos Férriz no ha sido situada en el mapa de la fotografía española del siglo XX y menos aún reconocida como ejemplo insoslayable de profesionalidad y virtuosismo técnico en el desempeño de su actividad durante décadas ${ }^{7}$. L os aspectos que se apuntan para soportar los frutos ejemplarizantes de esta relación mucho tienen que ver, precisamente y más allá de los aspectos técnicos y estéticos, con el rigor o la coherencia de las respectivas actitudes y aptitudes personales. la Arquitectura 1990”, en Arquitectos, 1990; y BERGERA Iñaki, "Racionalismo franciscano. Asís Cabrero: el clasicis mo abstracto", en Arquitectura Viva, 2005, 100, pp. 72-73

7. El único texto existente sobre Férriz se publicó en 1985 y tenía como pretexto rescatar y revisar su ambicioso trabajo fotográfico realizado para el Ayuntamiento de Madric en 1929. Publicado en dos partes, en él se aportan algunos datos biográficos básicos obtenidos a partir de una entrevista realizada por el autor del artículo a Jesús García Férriz en agosto de 1984. Cfr. ALAMINOS, Eduardo, "Fotografías de Férriz: Madrid, 1929 (I)", en Villa de Madrid, 1985, año 23, 83, Ayuntamiento de Madrid, Madrid, pp. 21-32 y -, "Fotografías de Férriz: Madrid, 1929 (II)", en Villa de Madrid, 1985 año 23, 84, Ayuntamiento de Madrid, pp. 17-28. Otra escueta mención a Férriz se puede leer en el Directorio de Fotógrafos en España, obtenida a su vez de anuarios comerciales de los años 30. Cfr. A.A.V.V., Directorio de Fotógrafos en España (1851-1936), tomo 2, Diputación de Valencia, Valencia, 2013, p. 512. Mientras que la fotografía española del siglo XX ha tenido y sigue actualizando sus respectivos relatos, historias y lecturas críticas, el ámbito concreto de la fotografía de arquitectura en nuestro país -y el descubrimiento de los fotógrafos involucrados en este desempeño- apenas está empezando a ser documentado y analizado en profundidad. Cfr. BERGERA Iñaki (ed.), Fotografía y arquitectura moderna en España, 1925-1965, Fundación ICO, La Fábrica, Madrid, 2014; BERGERA, Iñaki (ed.), Fotografía y arquitectura moderna. Contextos, protagonistas y relatos desde España, Arquia/Temas 39, Fundación Caja de Arquitectos, Barcelona, 2015 y A.A.V.V., Fotografía y arquitectura moderna en España. Antología de textos, Abada, Madrid, 2016.

8. ALAMINOS, Eduardo, "Fotografías de Férriz: Madrid, 1929 (I)", cit., p. 21.

\section{FÉRRIZ, APUNTES DE UNA VIDA DEDICADA A LA FOTOGRAFÍA}

Jesús García Férriz (Fig. 3) nació en M adrid el 9 de junio de 1900 en el seno de una familia trabajadora. La especial destreza que su padre adquirió en el trabajo de las telas en la sastrería que regentaba forjó de al guna manera la actitud esmerada y habilidosa que cultivó Férriz a lo largo de su carrera profesional. Tras el temprano fallecimiento del progenitor, la familia se trasladó a vivir a un edificio de la calle R ecoletos. Su madre trabajó como conserje de la finca y Férriz consiguió también allí su primer empleo, en las oficinas de una fábrica de tejidos sitas en el mismo inmueble. Compaginaba estas tareas con las clases de auxiliar administrativo en la cadena de academias Cots, completando de esta manera su formación. Su interés inicial por la fotografía se solapaba con su pasión por la natural eza y la montaña. Durante sus frecuentes excursiones por la Sierra de Guadarrama en compañía de su familia y amigos realizaba numerosas fotografías que se conservan en los ál bumes familiares. Sin embargo, el desencadenante de su sal to definitivo a la fotografía como actividad profesional fue su ingreso a los dieciocho años, durante el servicio militar, en la B rigada O brera y Topográfica del Estado M ayor. Fotografiando a los quintos adquirió conocimientos y experiencia en el manejo de cámaras y objetivos. Pero fue también entonces cuando entró en contacto con la arquitectura8:

"Trabajó en el Ayuntamiento para la Dirección General de A rquitectura, donde conoció a los arquitectos Giner de los Ríos, L uis B ellido y García M ercadal. Tanto en el Ayuntamiento como en la B rigada Topográfica, la mayor parte de los trabajos consistían en fotografiar planos, aunque su afición le lleva a fotografiar una iglesia o capilla que había por la Ciudad Lineal, trabajo que vio el arquitecto Benito Guitar, proponiéndole para fotógrafo de la revista Arquitectura, donde aparecen fotografías suyas a partir del número de octubre de 1928". 
Establecido en 1925, de facto, como uno de los primeros fotógrafos industriales de M adrid ${ }^{9}$, trabajó y se relacionó efectivamente con numerosos arquitectos ${ }^{10}$, con anterioridad incluso a su colaboración con la revista Arquitectura ${ }^{11}$. Casado ese mismo año con Francisca A mador, los cuatro hijos del matrimonio -y especialmente su hijo A lberto- trabajarían activamente, en distintas etapas, en el negocio de su padre. Su primer gran encargo fue un conjunto de fotografías de M adrid destinadas a ilustrar el trabajo M emoria: Información sobre la ciudad (Fig. 4), un ambicioso libro de investigación y documentación publicado en 1929 por el Ayuntamiento de la villa ${ }^{12}$. Férriz se sentía especialmente orgulloso de una de aquellas fotografías, la que muestra el recién inaugurado edificio de la Compañía Telefónica Nacional de España en la Gran Vía madrileña, obra de I gnacio Cárdenas y L ouis S. Weeks (Fig. 5). La fotografía, de gran calidad, es fruto de la unión en la ampliadora de varias imágenes diferentes -obtenidas sobre placas de 13x18-, un trabajo artesanal y meticuloso a juzgar por los medios técnicos disponibles entonces en España. Esta y el resto de las fotografías que realizó para la referida publicación municipal se encuentran depositadas en el M useo de la Historia de M adrid.

Férriz no combatió en el frente durante la Guerra Civil pudiendo gracias a sus encargos fotográficos mantener a su familia. Entre otros, realizaba retratos a los milicianos que, coloreados y tratados convenientemente, insertaban en sus sortijas y medallas. Tras la guerra y como hicieran también otros conspicuos colegas profesionales como Joaquín del Palacio 0 J uan Pando Barrero ${ }^{13}$, realizó fotografías para la Dirección General de Regiones Devastadas y R eparaciones, dependiente del M inisterio de la Gobernación, publicadas en Regiones Devastadas, la revista oficial del organismo ${ }^{14}$. Poco a poco fue ganándose una reputación y, por tanto, clientes y encargos tanto en el ámbito de la arquitectura -donde se inscribe su fructífera colaboración con A sís Cabrero que aquí nos interesa-, la ingeniería o la industria, como en otras cuestiones vinculadas al mundo de la publicidad, incluyendo la iluminación de monumentos o el al umbrado de calles. Un conjunto de reportajes del teatro de la Ó pera, el teatro A maya y el teatro Real de Madrid serían también de especial mención, así como, a partir de 1950, el seguimiento de las obras de construcción del Valle de los Caídos a las órdenes del arquitecto Diego M éndez, responsable junto a Pedro $M$ uguruza del monumental proyecto ${ }^{15}$. Otro encargo significativo de aquellos años fue el seguimiento fotográfico de las obras de madrileño barrio de la Concepción, realizado por el mismo constructor del Valle de los Caídos, el promotor J osé B anús. A I ser obras subvencionadas, las estrictas certificaciones mensual es debían acompañarse de las respectivas fotografías que dieran fe del avance de las obras. Con el aumento creciente de la carga de trabajo en el estudio, su hijo A lberto -quien al principio se había limitado a acompañar a su padre como ayudante y a realizar trabajos de positivado de negativos como aprendiz- fue progresivamente asumiendo una clara responsabilidad en el estudio. Contaron también entonces con la ayuda de dos ayudantes, L uis Heredia y A ndrés, pero incluso las tres hijas del fotógrafo contribuyeron al negocio familiar encargándose, por ejemplo, de colorear las pequeñas imágenes que se proyectaban durante los intermedios de las películas proyectadas en los cines ${ }^{16}$.

En suma y al margen de los ejemplos citados y de la fructífera colaboración con A sís Cabrero, Férriz terminó concentrando mayormente su trabajo en encargos propios de la fotografía industrial, teniendo entre sus clientes a destacadas empresas como A groman 0 Phillips ${ }^{17}$. El fallecimiento de su esposa en 1966 sumergió a J esús García Férriz en una profunda depresión. El estudio cambió nuevamente de ubicación y su hijo A lberto terminó por hacerse cargo definitivamente del negocio familiar ${ }^{18}$, al tiempo que se introducía el color en los encargos fotográficos ${ }^{19}$. Férriz fue progresivamente abandonando la práctica fotográfica, centrándose acaso en algún trabajo puntual y en la atención administrativa del estudio. Fallecido en 1988, la marca fotográfica Férriz continúa actualmente en la figura de su nieto Alberto, quien en su casa-estudio de San Clemente, Cuenca, conserva el ingente archivo fotográfico de los Férriz.

\section{RIGOR DOCUMENTAL Y DESTREZA TÉCNICA}

Nos encontramos así ante un inexplorado archivo familiar privado de fotografía, un caso sin duda significativo para reconstruir los perfiles de la práctica profesional de la fotografía del siglo XX en España, sus técnicas y sus equipos. Como ocurre en el caso de Pando -un

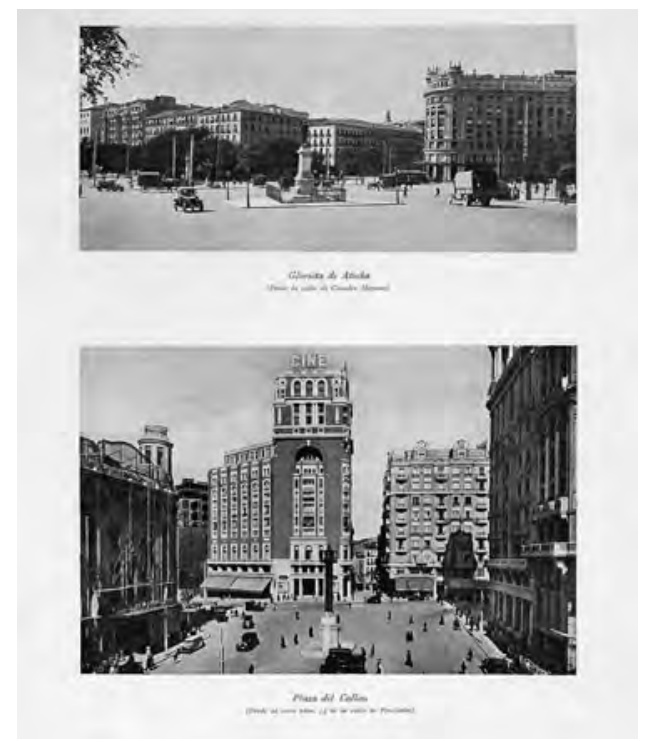

Fig. 4. Fotografía de la corredera Baja de San Pablo de Madrid (ca. 1929) publicada en el libro Memoria: Información sobre la ciudad. Año 1929 (Ayuntamiento de Madrid, Madrid, 1929). En RODRÍGUEZ SALMONES, Cristina (Coord.), Imágenes de Madrid. Fondos fotográficos del Museo Municipal, Ayuntamiento de Madrid, Madrid, 1984, p. 97

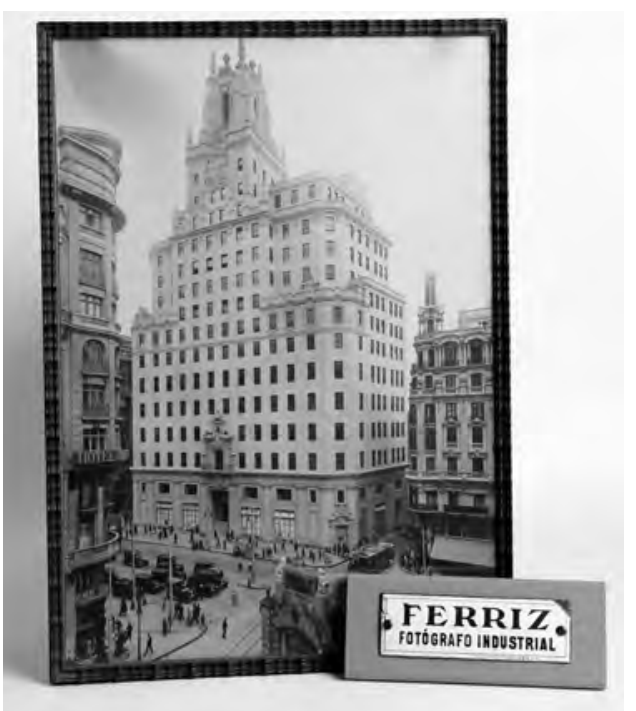

Fig. 5. Fotografía enmarcada del edificio de Telefónica en la Gran Vía madrileña (Férriz, 1929) junto a la placa de época del estudio. (C) Alberto Férriz (nieto).

9. La ubicación del negocio, especialmente en los primeros años, parece que varió significativamente. El primer estudio se ubicó en el número 12 de la calle Olózaga. Según consta en el referido Directorio de Fotógrafos en España en los años 1933-1935 se anunciaba como "artículos y material para la fotografía en la ciudad de Madrid en la C/ Niceto Alcalá Zamora, 58". Seguramente después de la Guerra Civil el estudio estuvo por poco tiempo en la calle Trafalgar hasta que se trasladó, junto al domicilio, al número 60 de la calle Alfonso XII, en frente del parque del Retiro. Finalmente, en 1966, se instaló en la calle Murcia, donde Férriz trabajó durante los últimos años de su carrera profesional. 
Fig. 6. Placas fotográficas originales del archivo Férriz. (C) Alberto Férriz (nieto).

Fig. 7. Fichas correspondientes a los negativos de encargos fotográficos de Asís Cabrero. (C) Alberto Férriz (nieto).

Fig. 8. Linhof Tecnhika de 9x12 y modelo anterior de madera para placas de $13 \times 18$. (C) Alberto Férriz (nieto).

10. Tenemos constancia por ejemplo de unas fotografías de 1926 de unas viviendas en Zaragoza del arquitecto Regino Borobio (Cfr. A.A.V.V., Regino y José Borobio. Arquitectura y fotografía. Zaragoza, 1923-1969, Institución Fernando el Católico, Zaragoza, 2015, p. 59) así como de haber colaborado especialmente con Luis Gutiérrez Soto: dos fotografías de la piscina la Isla en el Manzanares, de 1931, se publicaron en el libro Arquitectura Española Contemporánea de Carlos Flores (Aguilar, Madrid, 1961).

11. "Por la revista desfiló un gran número de excelentes fotógrafos -Byne, Supervía, Gil Miquel, Wunderlich, Antón, Lladó, Pando, Clavería, Soler, Torres Molina, Férriz...-que actuaron como colaboradores más o menos habituales en distintos periodos, aunque también aparecen muchas fotografías sin acreditar". GONZÁLEZ PRESENCIO, Mariano, "Los dibujos y las ilustraciones", A.A.V.V., en Revista Arquitectura [1918-1936], Colegio de arquitectos de Madrid Ministerio de Fomento, Madrid, 2001, p. 186. Y Alaminos puntualiza: "En la revista Arquitectura, Férriz publicó fotografías suyas desde el número de octubre de 1928 hasta e de noviembre de 1931, sobresaliendo una serie muy interesante sobre comercios madrileños en el número de julio de 1931". ALAMINOS, Eduardo, "Fotografías de Férriz: Madrid, 1929 (II)", cit., p. 28.

12. Se trata de un importante trabajo de recopilación de las actuación urbanas de la ciudad -destinado a servi de base documental para un concurso internacional de trazado viario y urbanización del extrarradio-dirigido por los arquitectos municipales Eugenio Fernández Quintanilla y Bernardo Giner de los Ríos, con la colaboración en la elaboración gráfica de Otto Czekelius y Francisco García Mercadal. De las 116 fotografías del libro algunas van firmadas por Laurent, Moreno, Ruiz-Vernacci y Aviación Militar, siendo las imágenes sin autoría, 84 en total, las que correrían a cargo de Férriz, tal y como indica Quintanilla en el prólogo. Cfr. A.A.V.V., Memoria: Información sobre la ciudad. Año 1929, Ayuntamiento de Madrid, Madrid, 1929 y RODRÍGUEZ SALMONES, Cristina (Coord.) Imágenes de Madrid. Fondos fotográficos del Museo Municipal, Ayuntamiento de Madrid, Madrid, 1984.

13. Sobre estos dos destacados fotógrafos de arquitec tura moderna en España, cfr. ZARZA, Rafael (ed.), Kin del (1905-1989), Fotografía de arquitectura, Fundación COAM, Madrid, 2007 y BERGERA, Iñaki, GONZÁLEZ, Beatriz, "La batalla moderna. Juan Pando, Photographe (1915-1992)", en Arquitectura Viva, 2015, 171, pp. 50-53.

14. Cfr. A.A.V.V., Arquitectura en Regiones Devastadas [catálogo de exposición], Dirección General de Arquitectura y Edificación, Centro de Publicaciones Ministerio de Obras Públicas y Urbanismo, Madrid, 1987.

15. Cfr. MÉNDEZ, Diego, El Valle de los Caídos: idea proyecto y construcción, Fundación de la Santa Cruz de Valle de los Caídos, Madrid, 1982.

16. Explica Alberto Férriz: "En los descansos en los cines se proyectaban anuncios a base de diapositivas de 4,5×6. Se trataba de una emulsión fotográfica en gelatina. Para que tuviera la suficiente consistencia se colocaban entre dos cristales. Estos tenían que ser cristales muy finos para que entraran en las máquinas de proyección". JIMÉNEZ, Cris tina, "Entrevista a Alberto Férriz (hijo)", Madrid, 4-4-2014 [documento inédito]. Estos trabajos se realizaban por encargo de agencias de publicidad como Publicitas o Alas.
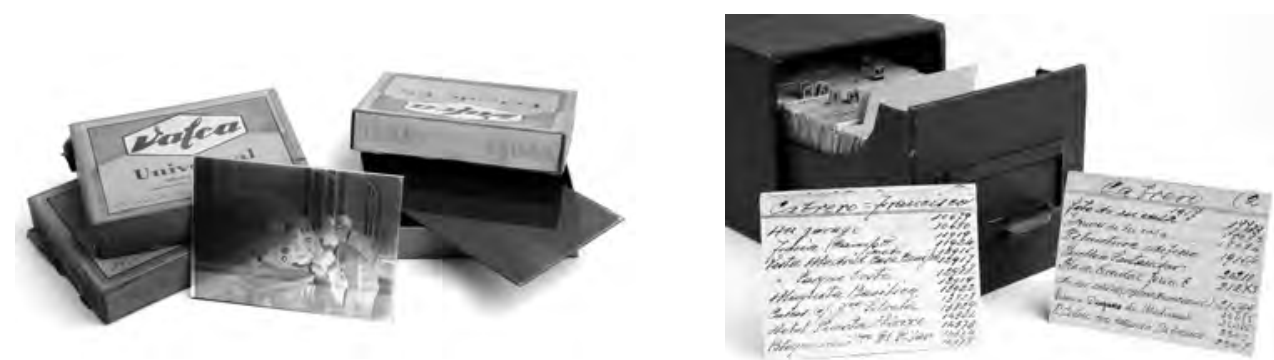

6

7

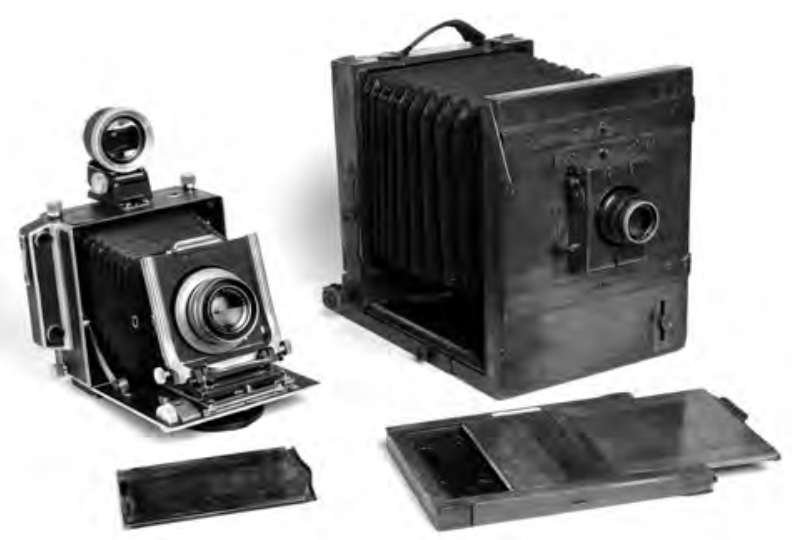

arquetipo profesional de alguna manera paralelo al de Férriz y cuyo archivo está depositado en el Instituto de Patrimonio Cultural de España- su archivo conserva únicamente negativos y placas pero no copias de época que terminaban siempre en manos de los clientes. Los primeros negativos del archivo se conservan sobre placas fotográficas de vidrio (Fig. 6) - $13 \times 18$ y 18x24- que Férriz comenzó a registrar ${ }^{20}$ a partir del número $12.000^{21}$ mientras que

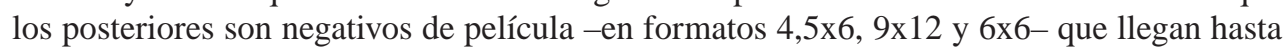
el número 38.000 (Fig. 7). A rrancan en el 12.000 ya que Férriz destruyó los negativos de las primeras placas fotográficas de $13 \times 18$ centímetros para reutilizar el vidrio en los referidos trabajos de publicidad para las salas de cine. M ediante baños de agua caliente el iminaba la emulsión fotográfica y utilizaban aquellos finos vidrios -entonces un material escaso y apreciado- para proteger las diapositivas de los anuncios que se proyectaban en la gran pantalla.

Férriz, como sus colegas Pando o Català-Roca22, fue progresiva y paulatinamente adquiriendo equipos, cámaras fundamentalmente, de gran calidad. L a naturaleza estrictamente profesional de su trabajo, unido al gusto por la técnica y el rigor óptico y visual de sus imágenes, le llevó a comprar - en la Casa R omán García de M adrid- cuerpos ciertamente sofisticados, conservados aún en el archivo familiar. Al comienzo de su ejercicio profesional empezó utilizando una cámara Ermanox para placas de 4,5×6 que gracias a su luminoso objetivo Ermostar $\mathrm{f} / 1,8$ le permitía seleccionar velocidades de obturación significativamente altas para la época. Pasadas dos décadas, en los años 50 adquirió una Linhof Tecnhika de 9x12 - en sustitución de un modelo anterior de madera para placas de 13×18-, una cámara de fuelle de gran formato muy apropiada para los reportajes de arquitectura por su versatilidad, reducido tamaño y sus grandes prestaciones que permitían con facilidad-gracias a un sistema de raíles- modificar el encuadre horizontal-vertical y especialmente corregir la perspectiva vertical, un aspecto clave para los estándares de calidad de la fotografía de arquitectura (Fig. 8). Terminó su carrera profesional utilizando una Rolleiflex, una cámara versátil de medio formato, empleando por último una Kodak Retina de $35 \mathrm{~mm}$ para sus fotografías personales. El fotógrafo no se limitaba a manejar estos equipos con destreza sino que también fabricó con gran pericia placas para montar objetivos, plantillas para los chasis - que permitían montar distintos tamaños de placas en las cámaras y poder así cambiar de formato- o la propia ampliadora que utilizaba en el estudio. Se trataba de una forma de trabajar, en suma, que combinada un riguroso conocimiento técnico con unos habilidosos procesos artesanales, dando como resultado un trabajo personal que terminó seguramente caracterizando al personaje y atrayendo y fidelizando a sus clientes, Cabrero entre otros. 
A pesar de considerarlo poco lucrativo debido al tiempo que debía invertir en el emplazamiento para realizar el reportaje del edificio correspondiente, Férriz - según ha relatado su hijo A lberto- disfrutaba enormemente con este género fotográfico. El trabajo de campo era arduo y hacendoso y perseguía buscar el momento del día, la luz y el punto de vista idóneo para mostrar la esencia de cada edificio. De esta forma y sin influencias de otros profesionales ni relacionarse con los círculos disciplinares propios - sociedades y salones fotográficos, agrupaciones, etc.- Férriz desarrolló una vida profesional autodidacta basada en la propia experiencia, el progresivo aprendizaje del oficio y la resultante madurez. Nos encontramos así ante un modo de operar estrictamente ligado a su personalidad, recta y rigurosa. Su carácter meticuloso y organizado se traslucía en la naturaleza del trabajado fotográfico. Sus fotografías de arquitectura estuvieron dotadas desde el principio de su trayectoria de una extrema pureza y contención, bañadas de un aura que sintetiza y condensa la arquitectura gracias al rigor de la técnica y a la sensibilidad compositiva de su mirada, tal y como apuntaba A laminos en relación a su extenso reportaje de M adrid de 192923:

"Las fotografías de J esús García Férriz se caracterizan por encuadres de gran precisión y por una captación escueta, casi azoriniana, del objeto fotografiado, aspecto o rasgo formal éste que le caracteriza como fotógrafo y que imprime un sello inconfundible a sus fotografías".

\section{SÍNTESIS SUPERPUESTAS: LA MIRADA DE FÉRRIZ SOBRE LA OBRA DE CABRERO}

Como adelantábamos al comienzo del texto, la sinergia col aborativa que se produce entre nuestros personajes, desbroza un caso único y paradigmático en la arquitectura moderna española. Si nos atenemos al papel estrictamente documental e instrumental de la fotografía de arquitectura, nos encontramos ante un trabajo clientelar satisfactorio, que cumple su cometido y colma las expectativas. Cabrero, como la mayoría de sus colegas generacionales, tenía una necesidad real y para nada pretenciosa de registrar con imágenes el fruto de su trabajo como proyectista y Férriz, aportando su saber-hacer cualificado y profesional, respondía con rigor y satisfacción a su cliente. Cabrero disponía así de juegos de fotografías ${ }^{24}$, impresas casi siempre sobre papel baritado (gelatina de plata) de $18 \times 24 \mathrm{~cm}$, que después enviaba a las publicaciones o las revistas nacionales 0 extranjeras cuando le eran requeridas o para documentar, al final de su trayectoria, su obra magna Cuatro libros de arquitectura ${ }^{25}$. Sin embargo, el interés analítico y justificativo de este caso de estudio, encuentra acentos propios cuando nos enfrentamos a él con interrogantes. Conociendo la notable calidad del resultado, ¿por qué Férriz no se procuró otros clientes de entre los compañeros de Cabrero? ¿Por qué, salvo contadas excepciones, Cabrero no trabajó con otros fotógrafos? ¿Qué tienen las fotografías de Férriz de la obra de Cabrero que, satisfecha la descripción documental y visual del proyecto, parezcan estar 'construidas' con la misma sensibilidad y contención que esboza la arquitectura que retrata?

A penas ha trascendido - al no haber correspondencia ni otros documentos personales que los relacionaran en los archivos respectivos- cual fue el modus operandi del trato entre Férriz y Cabrero. Sí que sabemos que Cabrero dejaba hacer. Salvo casos contados ${ }^{26}$, no imponía restricciones ni dirigía coercitivamente la mirada de Férriz. El carácter del arquitecto, sobrio y seco pero afable y cercano, se superponía sin fricciones con la personalidad modesta y reservada del fotógrafo. Rebosantes de afinidad, ambos entendían su papel y lo respetaban. Pero esto no era necesariamente lo habitual, ni antes ni ahora. Fisac, arquitecto enfático y programático, buscó la colaboración de diferentes fotógrafos a lo largo de su dilatada trayectoria: Kindel, Català-Roca, M üller, Schommer, Susana o Focco, por citar algunos. Razones de amistad 0 conveniencia y seguramente también de desencanto estarían detrás de esta diversificación. A burto, compañero profesional de Cabrero - con quien firmó en colaboración el proyecto del M onumento a la Contrarreforma (1948), la Catedral de M adrid (1950) y especialmente la sede central de los Sindicatos (1950)-, en un extremo opuesto de despreocupación ${ }^{27}$, dejaba hacer a su amigo Kindel a quien introdujo de hecho en los círculos de la Revista Nacional de Arquitectura gracias a la amistad de éste con $\mathrm{C}$ arlos de $\mathrm{M}$ iguel ${ }^{28}$. A lejandro de la Sota, por referirnos a un tercer caso de otro compañero generacional, tras colaborar con Kindel en sus primeros proyectos, pasó a fotografiar él mismo sus propias obras, sosteniendo acaso que la continuidad de pensamiento racional, abstracto y poético entre el proyecto, la obra y el relato visual de ésta no se podía romper por la aparición de una mirada ajena al propio proceso.
17. Se pueden citar reportajes para Benito Delgado -empresa dedicada a la electrónica-, Agroman -empresa dedicada a la obra civil, edificación y obra industrial-, o Philips, con reportajes de aparatos eléctricos, radios, tocadiscos y fotografías de iluminación como las que hicieron para el primer alumbrado que se instaló en el estadio Santiago Bernabéu.

18. Otros ejemplos, en el contexto de la fotografía de arquitectura moderna en España, de esta continuidad familiar del oficio serían Albrecht Schommer Koch -fotógrafo alemán afincado en Vitoria y autor, entre otros, del reportaje de la Iglesia de la Coronación de Miguel Fisac- de quien aprendió su hijo Alberto Schommer desarrollando posteriormente una fructífera carrera más allá de la arquitectura y Cristóbal Portillo, cuyo estudio profesional tuvo continuidad gracias a sus tres hijas y su hermano Lorenzo Portillo tras el prematuro fallecimiento del fotógrafo en 1957.

19. Inicialmente los Férriz confiaron el positivado color de las fotografías a laboratorios externos hasta que, tras un tiempo de largas y penosas pruebas -en palabras de su hijo Alberto- consiguieron al comienzo de los años 70 hacerlo ellos mismos.

20. El registro del archivo está inventariado por clientes mediante pequeñas fichas de $6 \times 10$ centímetros ordenadas alfabéticamente según el nombre de los mismos. Clasificados por fecha, el fotógrafo escribía en las fichas la signatura de negativos de los trabajos realizados para cada cliente, acompañando la numeración por una pequeña descripción del reportaje en cuestión.

21. El archivo fotográfico de Cabrero incluye las fotografías - una de exterior o dos de interiores- realizadas por Férriz de la Residencia para Educación y Descanso en San Rafael, Segovia. La numeración de estas $-10.293,10.300$ y 10.301- efectivamente nos remite a los negativos que fueron destruidos por Férriz ya que no hay constancia de os mismos en su archivo.

22. Sobre el archivo y los aspectos técnicos del trabajo fotográfico del célebre fotógrafo catalán, cfr. ORPINELL, Jaume, "Archivos de fotografía de arquitectura: el caso de Català-Roca", en A.A.V.V., III Jornada de Arquitectura y Fotografía 2013, Institución Fernando el Católico, Prensas de la Universidad de Zaragoza, Zaragoza, 2014, pp. 13-42.

23. ALAMINOS, Eduardo, "Fotografías de Férriz: Madrid, 1929 (II)", cit., p. 27.

24. La compenetración entre Cabrero y Férriz era tal que el fotógrafo no facilitaba previamente al arquitecto hojas de contactos para que fuera él quien eligiera las imágenes a positivar o sus reencuadres -como sí hacían Coderch y Català-Roca, por ejemplo- sino que directamente le entregaba las copias que consideraba representativas del proyecto, generalmente entre 5 y 10.

25. Cfr. CABRERO, Francisco, Cuatro libros de arquitectura, Fundación Cultural COAM, Madrid, 1992.

26. En una ocasión, tal y como ha relatado su hijo Alberto, Cabrero indicó a Férriz que debía fotografiar su casa de Puerta de Hierro a una determinada hora del día, en la cual la luz que entraba por una ventana de su casa, era tamizada por la silueta de un rosal del jardín. Cfr. JIMÉNEZ, C., op. cit.

27. "Lo de Kindel lo hacía porque me lo pedían, Carlos de Miguel o quien fuera. Yo por propia iniciativa no fotografío cosas mías". Rafael Aburto, en BERGERA, Iñaki, "Conversaciones con Rafael Aburto", Madrid, 1999 [documento inédito].

28. Cfr. ZARZA, Rafael, "Las palabras nos ocultan la arquitectura", en ZARZA, R. (ed.), op. cit., p. 11. 


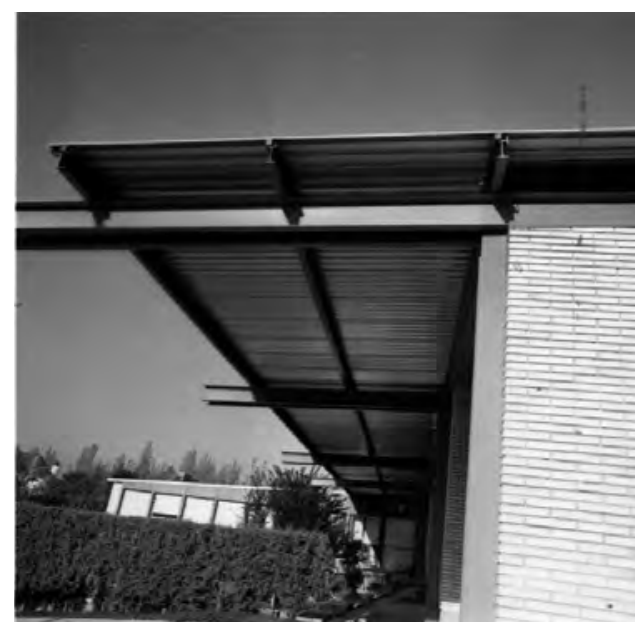

9

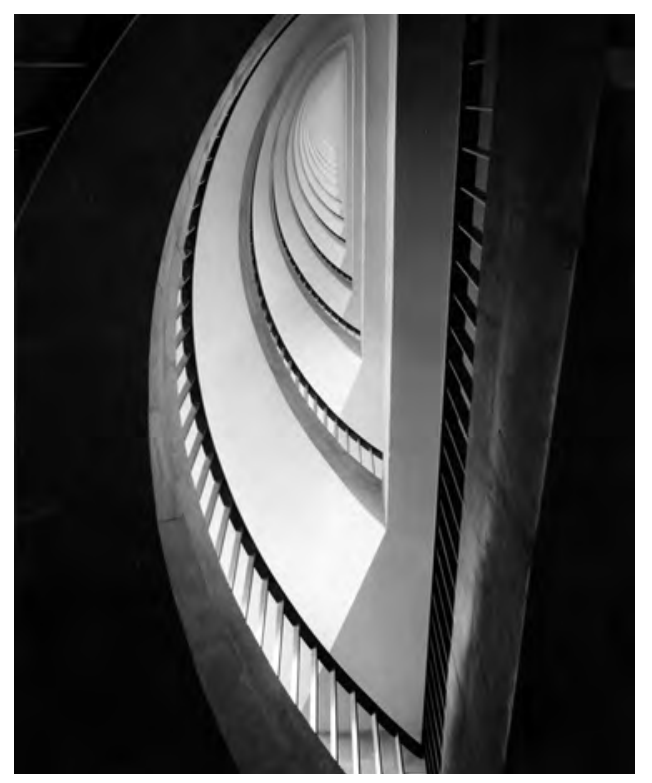

10

Fig. 9. Fotografía de Asís Cabrero de su casa en Puerta de Hierro, Madrid, 1961. (c) Familia Cabrero. AGUN/273.

Fig. 10. Escalera principal de la Casa Sindical (Madrid, 1950 1955). Arquitectos: Francisco Cabrero y Rafael Aburto. Fotó grafo: Férriz. (c) Familia Férriz. AGUN/273.

29. Cfr. FOCHS, Carles, Coderch, fotógrafo, Fundación Caja de Arquitectos, Barcelona, 2000.

30. El interés de Cabrero hacia la fotografía como instrumento de representación arquitectónica le llevó a utilizar en no pocas ocasiones el fotomontaje para previsualizar sus propuestas en concursos de arquitectura. Así sucedió po ejemplo en los proyectos del Monumento a Calvo Sotelo (Madrid, 1955) o el Mausoleo de Karachi (Pakistán, 1958).

31. Un caso particular es la fotografía fugada de la escalera principal que recorre la fachada posterior de la Casa Sindical (Madrid, 1950-1955), siendo que la escalara es un elemento que predispone a este tipo de juegos visuales y formales.

32. En la primavera de 2016 tuvo lugar en Madrid una exposición retrospectiva sobre la dimensión arquitectónica en la fotografía de Francisco Gómez. Cfr. MARTín Alberto (ed.), Archivo Paco Gómez. El instante poético y la imagen arquitectónica [catálogo de exposición], Comunidad de Madrid, Madrid, 2016.
Entre la desinhibición de A burto, el frenesí de Fisac, y el pragmatismo Sotiano, nos encontramos así con la mesura contenida, franciscana, de Cabrero y la de su contraparte, Férriz. La figura tranquila de Cabrero, nada impositiva, dio completa libertad a Férriz para que este desempeñara su trabajo. L a consiguiente compenetración hizo seguramente tan perdurable esta relación en el tiempo. Efectivamente, Cabrero 'raptó' para sí a Férriz, nos atrevemos a especular, porque las fotografías, pareciendo no tener 'nada especial', para Cabrero tenían todo lo que esperaba de ellas. Y sin embargo, como Sota y no digamos $\operatorname{Coderch}^{29}$, también Cabrero era fotógrafo. Desde su viaje iniciático a Italia en 1941 y durante los viajes que le llevaron a dar la vuelta al mundo durante los años 50 y 60 utilizó su cámara - primero una Zeiss I kon y después una Bronica de medio formato- como eficaz instrumento analítico y documental. Salvo un reportaje que él mismo hizo de su propia casa (Fig. 9), la segunda que construyó en Puerta de Hierro (M adrid, 1961), Cabrero supo respetar la autonomía y la especificidad de un cometido noble y sumamente difícil como es trasladar la experiencia tridimensional del espacio a una imagen impresa en papel, máxime cuando las fotografías que recibía de Férriz coincidían plenamente con su propio y formado paradigma de narrativa visual arquitectónica ${ }^{30}$.

\section{INTERDEPENDENCIAS ENTRE LA ARQUITECTURA Y SU IMAGEN}

La fortuna crítica de Cabrero y su arquitectura es circunspecta y se condensa en torno a unas pocas palabras clave: abstracción plástica, sobriedad constructiva, clasicismo abstracto, esencial ismo simbólico, osadía tranquila, liviana monumentalidad, estructuralismo reticular, funcional ismo prismático, etc. La valoración de una fotografía, entendida como constructo formal, puede de alguna manera apropiarse y solaparse con las características del objeto que retrata. En la fotografía de arquitectura, quizá como en ningún otro género de esta disciplina, esta fusión se hace más pal pable y en el caso que nos ocupa se expresa con enorme claridad. No hay en Férriz, salvo contadas excepciones ${ }^{31}$ (Fig. 10), contrapicados o escorzos forzados. La fotografía, como sistema de representación espacial, se ajusta fielmente a la norma geométrica y perspectiva del espacio euclidiano. La fotografía de Férriz es así sobria, esencial, limpia, rítmica y formalista como la arquitectura de Cabrero. Estas características, insistimos, vienen de al guna manera implícitas en los propios proyectos, pero el éxito reside aquí en la capacidad de condensar conceptual pero también formal e incluso asépticamente la esencia de lo fotografiado. Férriz, como Cabrero, borra y limpia, elimina lo particular para llegar a lo sustancial.Y por borrar, se borra a sí mismo. Las fotografías de Férriz, al contrario de lo que podemos decir de sus acreditados col egas $\mathrm{C}$ atalà-Roca, $\mathrm{K}$ indel o Francisco Gómez, difuminan las huellas delatoras del dedo que dispara. Descubrimos a Férriz en su anonimato. La condición y enfoque 'industrial' de su negocio evidencian acaso la radical modernidad de la eficiencia funcionalista de la arquitectura. Cabrero no quiso un 'artista' tras la cámara como él mismo no perseguía serlo oculto tras los planos. Cuanto más aparentemente aséptico, riguroso y desapasionado sea el retrato, paradójicamente, más se revelará el alma de la modernidad que esconde y persigue. Y no fue Férriz mejor fotógrafo que los referidos compañeros: fue el fotógrafo que Cabrero necesitaba.

Férriz y Kindel 'atacan' con la cámara el grupo de viviendas Virgen del Pilar (M adrid, 1948) desde el mismo escorzo (Fig. 11). La cadencia estructural y portante de los rítmicos muros medianeros de carga parece reblandecerse en la imagen de Kindel si la comparamos con la pulcra toma de Férriz que corrige ópticamente las verticales, elimina datos del contexto y busca la luz precisa para resal tar mediante las sombras los contrafuertes de arriostramiento laterales. En el diario Arriba (M adrid, 1960-1962) Férriz sitúa el trípode enfrentado a la fachada principal. La retícula estructural de la fachada del edificio sirve de falsilla para Ilenar frontalmente el visor invertido de la Linhof Tecnhika. Sin apenas aire al rededor de la fachada la toma es un alzado plano que rehúye la perspectiva. La fotografía es, de esta manera, un homenaje puro y contenido a la esencia plástica, reticular y estructuralista, del edificio (Fig. 12). Por el contrario, Francisco Gómez ${ }^{32}$ se escora y atrinchera como buen francotirador hasta componer una bella fotografía - que ocupó la portada del número 61 de la revista Arquitectura (1964) (Fig. 13)- en la que reconocemos antes al "poeta de paredes cochambrosas", según sus propias palabras, que a quien, junto al arquitecto César OrtizEchagüe, podríamos apadrinar como el ' $M$ ies español' si nos atenemos a la implícitas connotaciones y aspiraciones de la arquitectura de hierro y ladrillo que Cabrero proyectó en los años 60. Férriz desaparece porque su fotografía no deja narrativamente espacio para hacer 


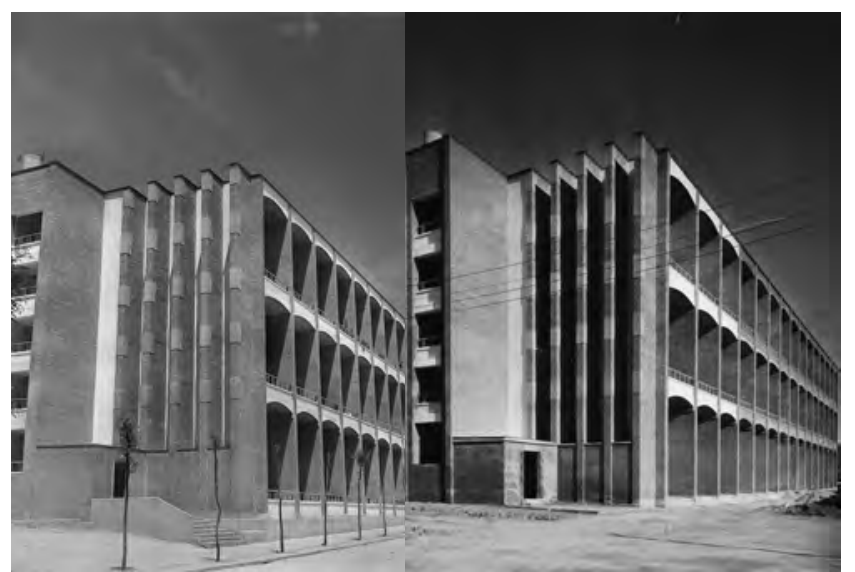

11

presente al autor, inundada como está de arquitectura y solo de arquitectura. La coreografía procedimental y metodológica implícita en la obtención de cada toma -la búsqueda y elección del encuadre y punto de vista, la medición precisa de la luz, el empleo de filtros para oscurecer el cielo y resaltar los volúmenes luminosos, la rigurosa construcción técnica de la imagen (profundidad de campo, exposición, enfoque, etc.)- acrisola paradójicamente de forma subjetiva la identidad objetiva de la arquitectura.

No hay espacio ahora para ahondar pormenorizadamente en este extenso legado de imágenes -incluyendo su difusión en las revistas de época-, ni tan siquiera en la narrativa secuencial implícita internamente en cada uno de los reportajes, algunos de ellos prolijos y exhaustivos como las 49 fotografías de la construcción del Pabellón de Cristal de la Casa de Campo (M adrid, 1964) (Fig. 14). Recorriendo en cualquier caso los 25 años de su estrecha colaboración vemos como la fotografía de Férriz se acompasa y actualiza a la par que lo hace la arquitectura de Cabrero. Desde los primeros proyectos más masivos, plásticos y escenográficos - como la I Feria N acional del Campo (M adrid, 1949) (Fig. 15)- que se retratan de una forma más subjetiva y pintoresca, artística si se quiere, se alcanza progresivamente en el plazo de apenas una década una arquitectura en ocasiones igual de monumental pero ligera y tecnológica - por ejemplo el proyecto de la Escuela Nacional de Hostelería ( $M$ adrid, 1957)- que Férriz fotografía sintéticamente, sin retóricas, con la referida desnudez, pureza y sobriedad. ¿Descubriría acaso un erudito Cabrero matices y atributos en su propia arquitectura al recibir y observar las fotografías de Férriz? ¿Seguiría viendo quizá aquellas austeras imágenes en clave pictórica, geométrica, neoplasticista o metafísica? Entendida la fotografía de arquitectura como lenguaje $\mathrm{e}^{33}$, como una interpretación visual de raigambre abstracta de la propia figuración arquitectónica, ¿no sería esta reiteración -formalización visual de la forma construida- la que llevaría a Cabrero a reafirmar su discurso arquitectónico o establecer controlados y medidos cambios de rumbo en su itinerario proyectual? A tenor de la evolución de su arquitectura -y de los citados matices observables en la fotografía de Férriz- nos atrevemos a decir que sí, que la fotogenia y la consistencia visual implícita en su obra sedimentó progresivamente la coherencia de su trayectoria. Imaginación, intenciones, ideas, realidades construidas y fotografías: como supo ver Climent Ortiz todo parece confluir, en Cabrero, en torno al universo de la imagen ${ }^{34}$ :

"Si pensamos en la capacidad que tiene Cabrero de volver una y otra vez sobre los mismos temas en-
tenderemos ese sistematismo, esa preocupación por un mundo ordenado, quieto, intemporal. Como si el
paisaje interior de sus edificios quisiera continuarse hacia un exterior de imaginación y visión, donde idea
y realidad se fundiesen en una misma imagen".

Las intenciones fotográficas de Férriz, por tanto, parecen solaparse y estimular las interpretaciones respectivas por parte de Cabrero. Cabrero y Férriz, Férriz y Cabrero, estimularon recíprocamente esa mirada intensa de natural eza creativa a la que se ha referido Helio Piñón ${ }^{35}$ :

"L a mirada intensa, aquella que caracteriza la práctica del arte, no se centra en identificar al go con existencia propia, sino en construir una realidad genuina a partir de valores del sujeto que los atributos sensibles de lo observado estimulan. M irar con intención es reconocer en el objeto de la experiencia algo que no es

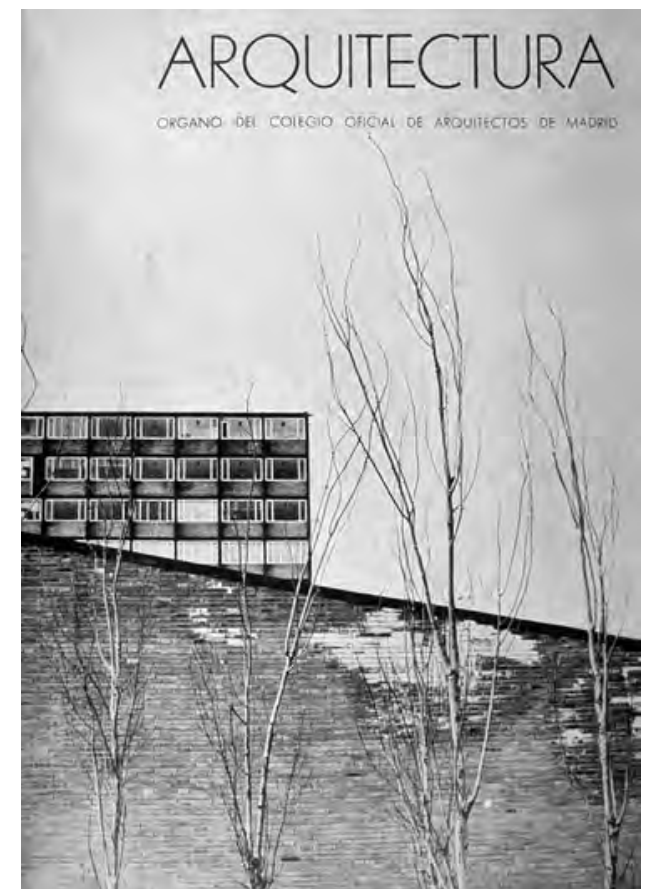

13

Fig. 11. Grupo de viviendas 'Virgen del Pilar’ (Madrid, 1948). Arquitecto: Francisco Cabrero. Fotografías de Kindel (izquierda) y Férriz (derecha). ZARZA, Rafael (ed.), Kindel (19051989), Fotografía de arquitectura, Fundación COAM, Madrid, 2007, p. 88 y @ Familia Férriz. AGUN/273.

Fig. 12. Edificio del diario Arriba (Madrid, 1960-1962). Arquitecto: Francisco Cabrero. Fotógrafo: Férriz. (C) Familia Férriz. AGUN/273.

Fig. 13. Portada del número 61 de la revista Arquitectura con una fotografía de Francisco Gómez del edificio Arriba (Madrid, 1960-1962) de Francisco Cabrero.

33. Ezra Stoller, maestro de la fotografía de arquitectura, explicó de forma canónica esta analogía de la fotografía como lenguaje, su papel intermediador y comunicativo entre el arquitecto y el receptor de las imágenes: "Para comprender verdaderamente una obra de arquitectura a través de un recurso intermedio, hay que aprender a leer la foto con tanto cuidado como un texto 0 un conjunto de dibujos. Entonces, dada la apreciación, el entendimiento y la imaginación necesaria, es posible que uno pueda experimentar de primera mano el placer personal de percibir una idea". STOLLER, Ezra, "La fotografía de Ezra Stoller y el lenguaje de la arquitectura", en Perspecta, The Yale Architectural Journal, 1963, vol. 8, p. 44.

34. CLIMENT, J., op. cit., p. 12.

35. PIÑóN, Helio, Miradas Intensivas, Edicions UPC, Barcelona, 1999, p. 351. 


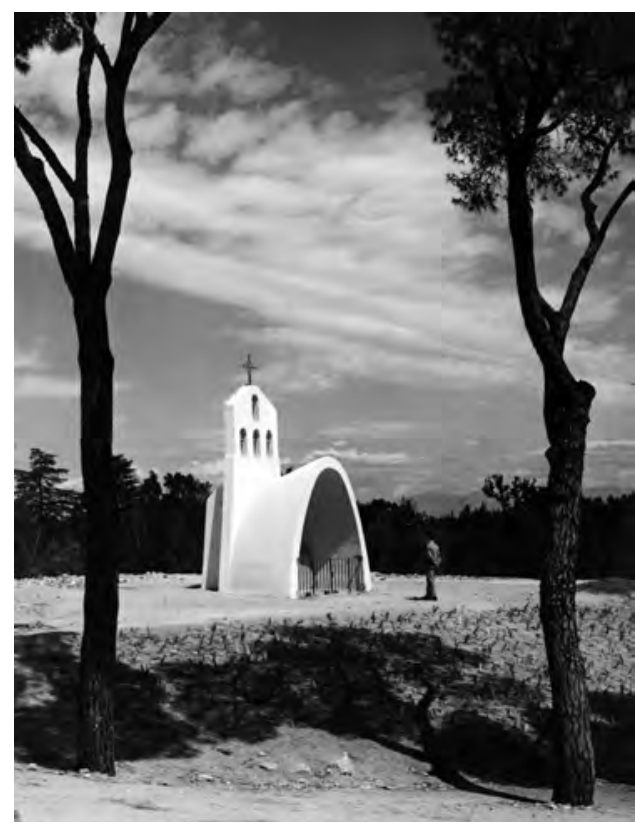

14

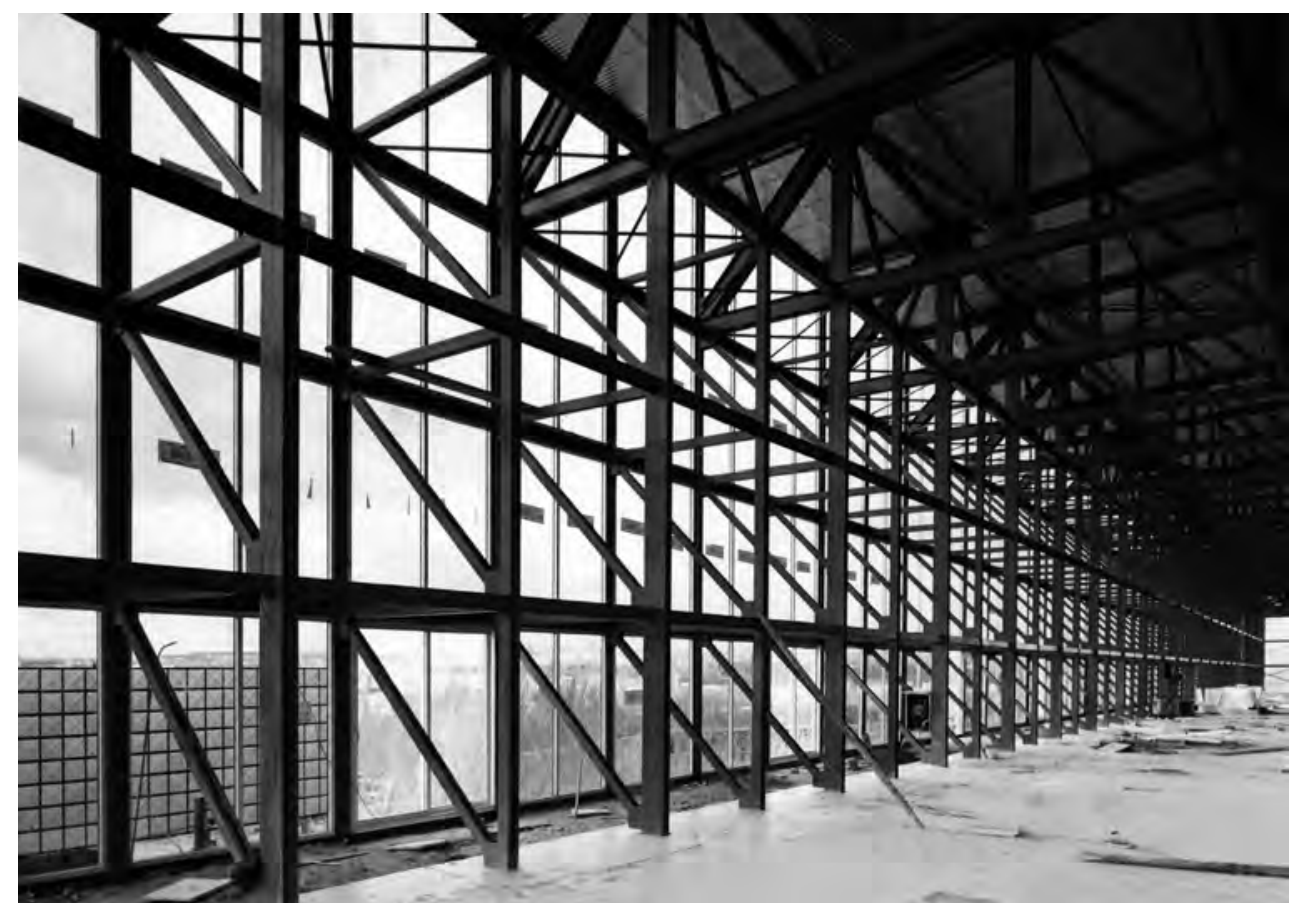

15
Fig. 14. Pabellón de Cristal en la Casa de Campo (Madrid 1964). Arquitectos: Francisco Cabrero, Luis Labiano y Jaime Ruiz. Fotógrafo: Férriz. (C) Familia Férriz. AGUN/273.

Fig. 15. Capilla de la Feria Nacional del Campo (Madrid 1948). Arquitectos: Francisco Cabrero y Jaime Ruiz. Fotógrafo: Férriz. (C) Familia Férriz. AGUN/273.

36. CHÉROUX, Clement, Fotografie und Geschichte, Institut für Buchkunst, Leipzig, 2004.

37. "De un episodio limitado pero intenso de nuestra arquitectura nos han quedado imágenes que transmiten un legado de forma y construcción arquitectónicas, y que van más allá: comunican la enorme voluntad de ser moderno". ISASI, Justo, "Por un puñado de fotos", en Arquitectura Viva, 2014, 166, p. 50. obvio ni manifiesto; es aflorar estructuras recónditas, de naturaleza formal y plástica, a través de la acción subjetiva. El objeto de la mirada no es, pues, algo con existencia previa a lo que el sujeto se aproxima con más o menos acierto, según su adiestramiento visual, sino que el objeto de la mirada se construye en cada caso, siendo el acto de mirar, cuando es intenso, esto es, artístico, una actividad creativa en sí misma".

Férriz, quizá, no sea mejor profesional - ni tan siquiera técnicamente- que Pando, CatalàRoca o M aspons-U biña, si endo estos los referentes del oficio profesional de la fotografía de arquitectura, un género apenas establecido y perfilado en la España de la segunda mitad del siglo XX, al ejado aún del paradigma y los estándares de las grandes firmas internacionales como Dell \& Wainwright, Stoller, Shulman o Hedrich B lessing. Pero si queremos seguir construyendo y justificando el papel no meramente instrumental que la fotografía de arquitectura tuvo en el devenir de la arquitectura moderna española debemos apuntalarlo sobre experiencias concretas que permitan conformar un discurso heterogéneo pero sintético. "La fotografía ha sido utilizada hasta ahora para reflexionar sobre la historia en lugar de para escribirla", sostiene el historiador de la fotografía Clement Chéroux ${ }^{36}$. En arquitectura, sin embargo, podemos decir que la historia de su discurso moderno se escribió desde el principio a golpe de obturador, mediante "un puñado de fotos" 37 elocuentes portadoras de su propio mensaje y magisterio. La hasta ahora inédita relación -intensa en la mirada y respetuosa en la transacción- entre Férriz y Cabrero, ejemplifica de forma paradigmática los entresijos de la tramoya visual que soporta el discurso de toda trayectoria arquitectónica. $L$ a arquitectura de Cabrero, su fortuna crítica, ha quedado impresa para siempre sobre gelatina de plata, trascendiendo incluso a la propia obra construida.

Iñaki Bergera. Arquitecto y Doctor por la ETSAUN en 1997 y 2002 y Master con premio extraordinario por Harvard. Su tesis doctoral fue premiada y publicada en 2005 por la Fundación Arquia. Ha sido profesor en la ETSAUN (1997-2007) y en la Europea de Madrid (2007-2009), siendo actualmente Profesor Contratado Doctor (acreditado Titular ANECA en 2013) en la EINA de la Universidad de Zaragoza. Es IP del Proyecto "Fotografía y Arquitectura moderna en España, 1925-65" (FAME) y comisario de la exposición homónima celebrada en el Museo ICO (PHE 2014) y de la exposición "Cámara y modelo" celebrada en Nuevos Ministerios (PHE 2016). Ha realizado estancias de investigación en el Getty de Los Angeles, el CCA de Montreal, el CCP de Tucson, la Universidad de Zurich y en Columbia University.

Cristina Jiménez. Arquitecta por la ETSA de Valladolid en 2010 y Máster en Arquitectura por la EINA de la Universidad de Zaragoza en 2014, con calificación Sobresaliente en su trabajo fin de máster sobre arquitectura y fotografía en España. Ha colaborado con el proyecto FAME realizando labores de documentación e investigación. En la actualidad está desarrollando su doctorado en la EINA compaginándolo con el ejercicio de la profesión de arquitecta en el ámbito de la empresa privada. 